\title{
Uma Estrutura Protetora Contra Capotamento e ImPaCto (R.O.P.S.) Para Ser Externamente Montada Sobre Um Veículo 4X4 - Projeto E TESTES
}

\author{
Henrique G. Moura ${ }^{1}$, Alessandro B. S. Oliveira ${ }^{2}$ \\ Universidade de Brasília Campus Gama \\ hgmoura@unb.br, $\underline{\text { abso@unb.br }}$
}

\section{RESUMO}

É comum na indústria encontrar aplicações de veículos $4 \times 4$, seja para transporte de passageiros ou carga, por trilhas e estradas em condições desfavoráveis tal que se possam esperar acidentes com risco de esmagamento de cabine. Para tais aplicações, recomenda-se a utilização de estruturas protetoras contra capotamento e impactos (ROPS), devidamente projetadas para cada veículo de modo a promover a segurança dos passageiros sem comprometer os critérios técnicos necessários para a correta utilização do mesmo.

Este trabalho apresenta resultados de um projeto solicitado por uma companhia brasileira do setor da mineração, voltado para a construção e montagem externa de um ROPS sobre um veículo $4 \times 4$, utilizado em trilhas, com elevado risco de acidentes com rolamento em altura, no interior de minas abertas.

Como parte importante para a futura homologação da estrutura, um protótipo foi construído e testado numericamente e fisicamente, pela Universidade de Brasília Campus Gama. Todas as análises de CAD/CAE, aqui mencionadas, foram realizadas pelos softwares comerciais CATIA V5 ${ }^{\circledR}$ e ANSYS ${ }^{\circledR}$. Os testes físicos foram realizados em uma bancada experimental, devidamente projetada para a aplicação de cargas nas três direções principais de choque, longitudinal, transversal e vertical.

Passada a etapa de análises numéricas, coleta de dados e aprimoramentos, o protótipo foi submetido a um teste piloto, tendo este sido montado no interior de um veículo $4 \times 4$ para capotamento proposital em pista, com o intuito de se avaliar as deformações reais de uma cabine, bem como a integridade do veículo.

Palavras chave: ROPS, capotamento, projeto.

\section{INTRODUÇÃO}

O projeto aqui apresentado é baseado no protocolo proposto pela $R M A$ - Ásia Automotive - (2014) e nas normas ISO 3471 (ABNT, 2000) e SAE J 1119 (2008). Ele se aplica a estruturas protetoras contra capotamento de veículos utilitários leves tipo pick-ups $4 \times 4$, em atendimento às necessidades da empresa solicitante.

As estruturas protetoras contra capotamento e impacto de montagem externa não são comuns no meio do automobilismo brasileiro, por serem pesadas e geralmente adotadas apenas em veículos off-road destinados a aplicações rurais; tratores, escavadeiras, caminhões, etc. Entretanto, o ROPS externo vem sendo aplicado à veículos $4 \times 4$ com caçamba, como é o 
caso das pick-ups, e até mesmo em veículos de passeio; neste caso a estrutura é montada solidariamente à carroceria.

Tais estruturas impedem que a cabine do veículo seja esmagada durante sucessivos rolamentos ou mesmo um choque causado sobre a cabine pelo tombamento do veículo. Nos estágios iniciais do projeto foram avaliadas as necessidades da parte solicitante no que se refere às características da estrutura, para que fosse possível estabelecer os requerimentos de projeto como se observa nas Figuras 1 e 2, abaixo.
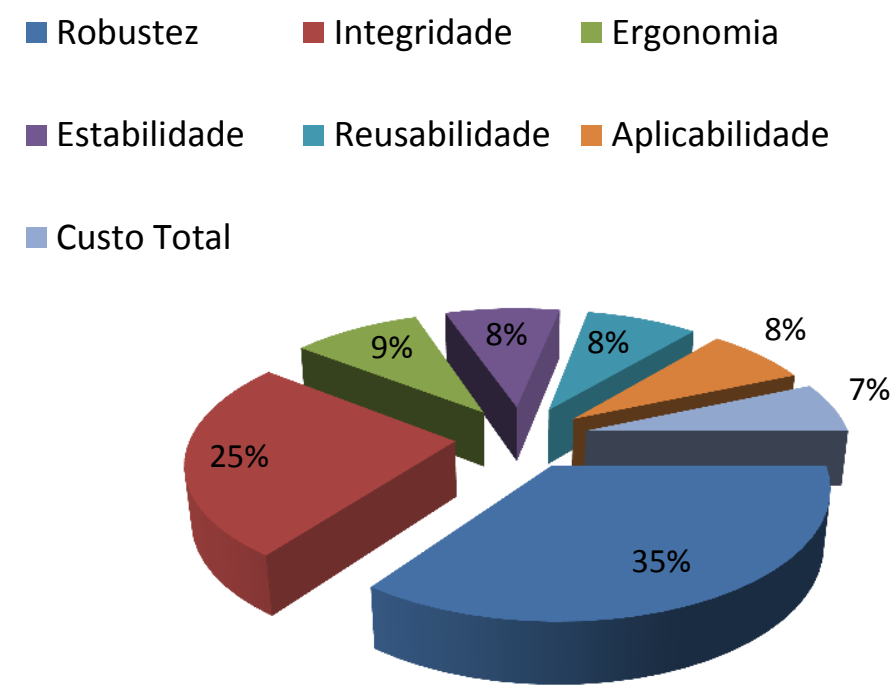

Figura 1 - Relevância de cada característica de projeto sobre o produto final ROPS.

Nos parágrafos seguintes será explicada cada uma das características adotadas para o produto final do projeto ROPS, começando pela robustez que representa a capacidade que o ROPS possui de resistir aos diferentes tipos de impactos e carregamentos, sob as condições de aplicação adotadas no projeto, protegendo os passageiros do veículo em uma situação de capotagem ou tombamento. Mecanismos como rigidez e deformações programadas serão investigados com o intuito de beneficiar esta característica, que possui vital importância para o projeto.

A aplicabilidade representa a flexibilidade que o ROPS possui em relação à sua aplicação e montagem em diferentes tipos de veículos. Tal característica se faz importante frente à grande quantidade de modelos de veículos utilizados atualmente pela empresa solicitante.

A ergonomia defende critérios indispensáveis para a utilização segura do ROPS, tal como a "interferência zero" do mesmo com o volume ocupado pelos condutores e passageiros do veículo. Outros critérios ligados à montagem do ROPS no veículo também devem ser verificados no projeto, pois o mesmo não pode reduzir as capacidades operacionais do condutor ou dificultar a saída dos ocupantes do veículo, em situações de emergência.

A integridade representa o grau de comprometimento estrutural do veículo devido à instalação do ROPS. A integridade deve ser analisada sob dois aspectos importantes: (1) em primeiro lugar, nenhuma modificação estrutural pode degradar as condições de funcionamento e segurança do veículo; (2) em segundo lugar, a reutilização do veículo após a retirada do ROPS, com menores reparos estruturais.

A reusabilidade a possibilidade de remoção e reutilização de um ROPS que, durante toda a vida útil do veículo no qual foi montado, não tenha sido mecanicamente solicitado. 
Esta característica reflete diretamente sobre os custos da fabricação dos sistemas ROPS, além de contribuir com as boas práticas ambientais de reaproveitamento de recursos materiais.

Os recursos tecnológicos atuais nos possibilitam trabalhar com diferentes soluções para o problema em questão, que vão desde a aplicação de barras solitárias de proteção (Rollbar) até soluções mais complexas, que integrem totalmente na estrutura do veículo, conferindo ao mesmo propriedades de resistência e segurança fora do padrão comercialmente aplicado (FRIEDMAN, 2000; HERST, FORREST, MEYER, 1998). Neste sentido, a característica de custo total foi utilizada para buscar melhores relações de custo-benefício considerando custos de tempo de montagem e recursos materiais - para o ROPS, atendendo aos critérios mínimos de segurança exigidos pelo projeto.

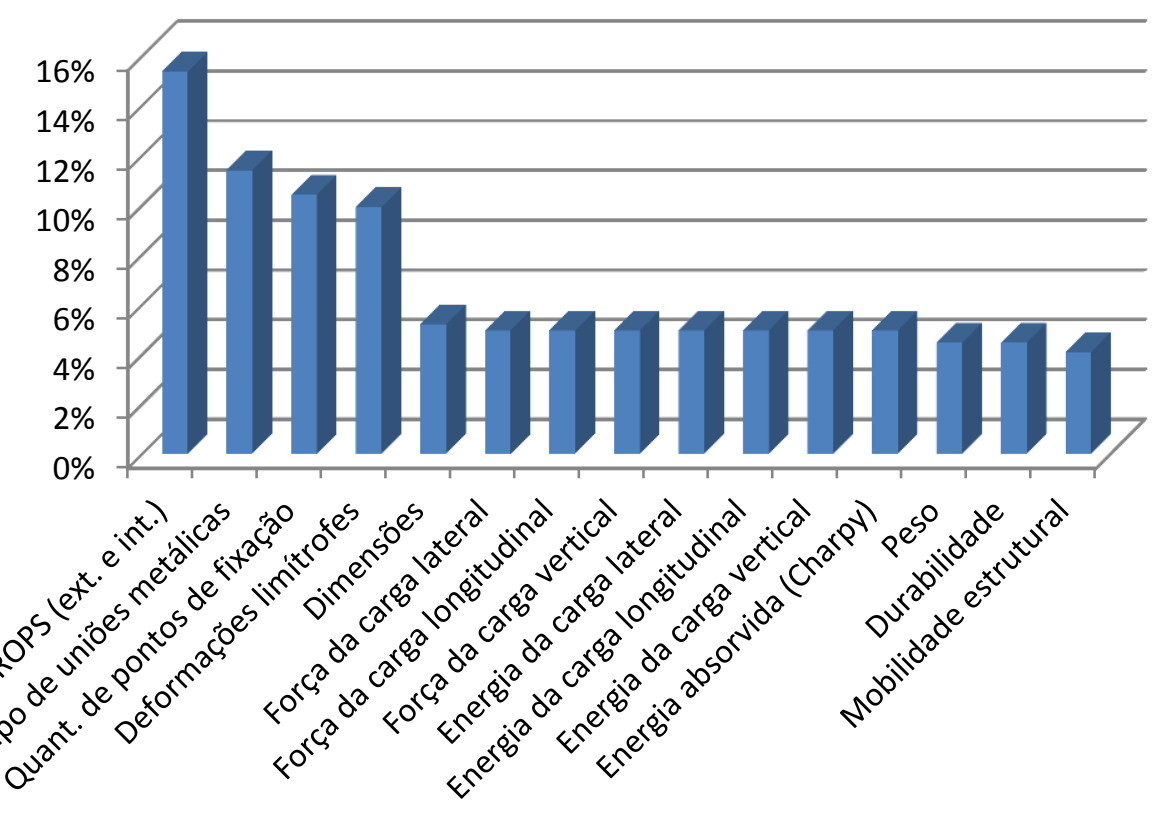

Figura 2 - Contribuição de cada requerimento de projeto sobre o produto final ROPS.

A Figura 2 traz todos os requerimentos técnicos adotados no projeto para a construção e testes dos protótipos ROPS. Este trabalho se limita a apresentar os principais resultados dos testes realizados para a confirmação do protótipo final ROPS, para os quais se destacam os requerimentos descritos abaixo.

A força da carga vertical é um dos critérios técnicos adotados pelas normas e protocolos técnicos vigentes, aplicados ao desenvolvimento de estruturas do tipo ROPS. Trata-se do parâmetro que define a robustez do ROPS em uma situação de meta-equilíbrio sobre o plano de apoio simulado vertical - posição invertida do veículo - ver Figura 4 a seguir.

A força da carga longitudinal é um dos critérios técnicos adotados pelas normas e protocolos técnicos vigentes, aplicados ao desenvolvimento de estruturas do tipo ROPS. Este parâmetro é um resultado direto da robustez do ROPS, quando solicitado por impactos frontais e posteriores - o ROPS não será idealizado para prover proteção ao veículo contra colisões frontais, mas naturalmente será projetado para resistir a esforços longitudinais que, em uma situação de capotagem com arrasto sobre o plano simulado vertical, possam ser aplicados sobre o ROPS. 
A força da carga lateral é também um dos critérios técnicos adotados pelas normas e protocolos técnicos vigentes, aplicados ao desenvolvimento de estruturas do tipo ROPS. Trata-se do parâmetro que define a robustez do ROPS em uma situação de tombamento ou capotagem do veículo, com impactos laterais, ou meta-equilíbrio sobre o plano simulado lateral - ver Figura 4 a seguir.

De maneira análoga à norma NBR NM-ISO 3164 (1995), este projeto necessitou de um estudo de ergonomia, voltado para os tipos de veículos tratados no mesmo, sobre o volume ocupado pelos passageiros, pernas, tronco, membros e cabeça. Por medidas de segurança, o ROPS não pode se chocar com este volume, mesmo após eventuais solicitações mecânicas. Para tal, foram analisadas as deformações limítrofes do ROPS, nas condições críticas de carregamento consideradas neste projeto.

Os resultados apresentados nas Figuras 1 e 2 revelam que cerca $80 \%$ das características observadas para o produto final deste projeto (ROPS) - Robustez, Integridade, Ergonomia e Estabilidade - estão voltadas para a segurança dos passageiros e dos condutores dos veículos abrangidos. As demais características envolvidas - Reusabilidade, Aplicabilidade e Custo Total - defensoras de cerca de $20 \%$ das parcelas de contribuição sobre os produtos finais do projeto ROPS, estão ligadas a critérios de ordem técnica, que visam aos benefícios ecológicos do sistema.

É importante ressaltar que toda a metodologia de concepção e projeto aqui apresentada foi exemplificada através da utilização de uma pick-up 4x4 MITSUBISHI L200 GL, fornecida pela empresa solicitante. Na etapa de concepção do produto, foram utilizados como ferramentas de apoio os seguintes softwares: CATIA e GID. Na etapa de elaboração do projeto, são usados os seguintes softwares de simulação numérica, baseado no método dos elementos finitos: ANSYS ${ }^{\circledR}$ e LS-Dyna ${ }^{\circledR}$. A Figura 3, a seguir, apresenta modelos CAD do protótipo de ROPS externo e sua respectiva montagem no veículo.

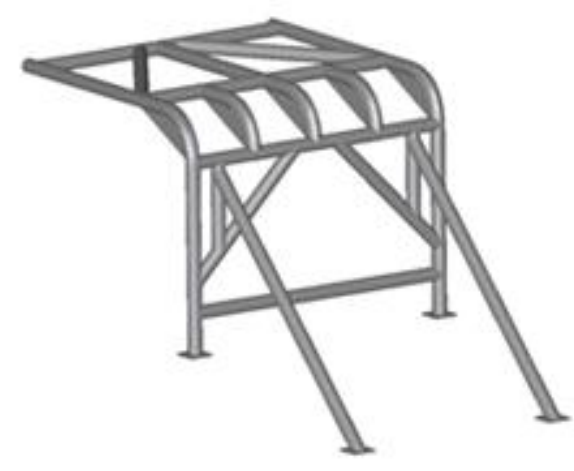

(a)

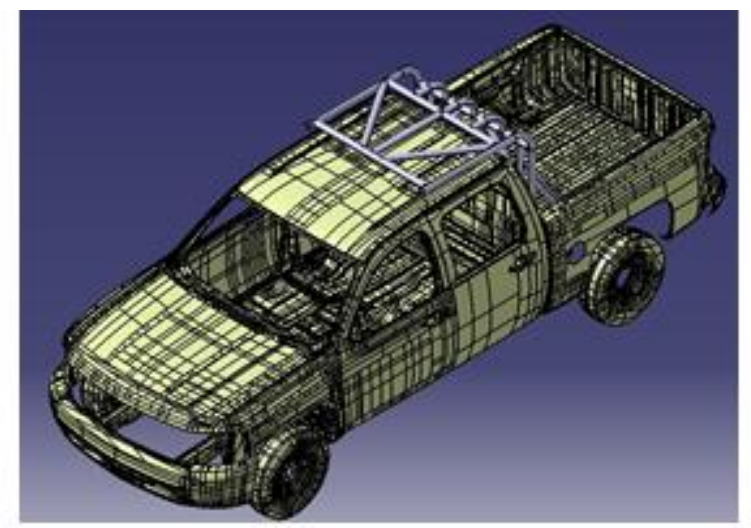

(b)

Figura 3 - (a) Protótipo preliminar do ROPS interno - modelado e testado; (b) visualização de uma montagem de ROPS externo em uma pick-up 4x4 MITSUBISHI L200 GL (modelo CAD exclusivamente realizado para as necessidades deste projeto).

Como se pode ver na Figura 4, o modelo de ROPS externo adotado neste trabalho trabalha em balanço sobre a caçamba do veículo. Esta estrutura precisa, para tal serviço, ser adequadamente fixada ao veículo de maneira a cobrir parcialmente a cabine, formando o chamado plano simulado vertical, que impede a cabine de ser esmagada durante um capotamento acidental. 


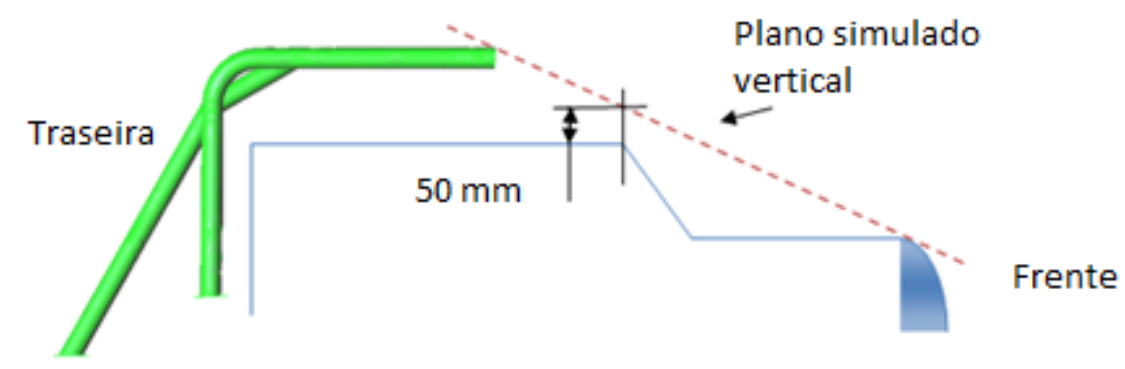

Figura 4 - Plano simulado vertical (protocolo RMA - Ásia Automotive). A estrutura ROPS forma juntamente com o capô do veículo, e motor, um plano que protege os ocupantes do veículo de um possível esmagamento da cabine, quando este se encontra em uma posição invertida sobre o solo.

No tópico seguinte estão apresentadas algumas informações importantes sobre o projeto ROPS constantes no protocolo RMA - Ásia Automotive (2005), bem como resultados dos testes numéricos e físicos realizados.

\section{INFORMAÇÕES GERAIS}

\subsection{O protocolo RMA - Ásia Automotive}

1.1.1 Quanto às cargas estáticas aplicadas (teste em bancada) e monitoramento de deflexões

De acordo com o sugerido pelo protocolo RMA - Ásia Automotive, os níveis de carga nas direções vertical, lateral e longitudinal estão especificados na Tabela 1, abaixo. Considera-se, para isso, como massa da pick-up em estudo (MITSUBISHI L200 GL), o valor de aproximadamente $\mathrm{M}=2.300 \mathrm{~kg}$, que é equivalente a massa da pick-up mais carga transportada (4 passageiros mais peso próprio do ROPS).

Tabela 1. Cargas de projeto para as estruturas de proteção.

\begin{tabular}{|c|c|c|c|}
\hline $\begin{array}{c}\text { Tipo de } \\
\text { carregamento }\end{array}$ & Carga vertical & Carga lateral & $\begin{array}{c}\text { Carga } \\
\text { longitudinal/frontal }\end{array}$ \\
\hline \multirow{2}{*}{ Carga de projeto } & $4,0 \times \mathrm{g} \times \mathrm{m}$ & $1,5 \times \mathrm{g} \mathrm{x} \mathrm{m}$ & $1,0 \times \mathrm{g} \times \mathrm{m}$ \\
\cline { 2 - 4 } & $90,1 \mathrm{kN}$ & $33,8 \mathrm{kN}$ & $22,5 \mathrm{kN}$ \\
\cline { 2 - 4 } & $9,2 \mathrm{ton}$ & $3,4 \mathrm{ton}$ & $2,3 \mathrm{ton}$ \\
\hline
\end{tabular}

Fonte: RMA - Ásia Automotive

onde "g" é a aceleração da gravidade (aqui considerada igual a $9,8 \mathrm{~m} / \mathrm{s}^{2}$ ) e "m" é a massa da pick-up mais a carga transportada. Outros níveis de carga poderão ser determinados para projetos de pick-ups distintas ao objeto de estudo, porém sempre obedecendo aos parâmetros fixados na $1^{\mathrm{a}}$ linha da Tabela 1 .

O dimensionamento estrutural, bem como os testes em bancada, foi realizado através de cargas aplicadas nos pontos indicados na Figura 5, abaixo. 


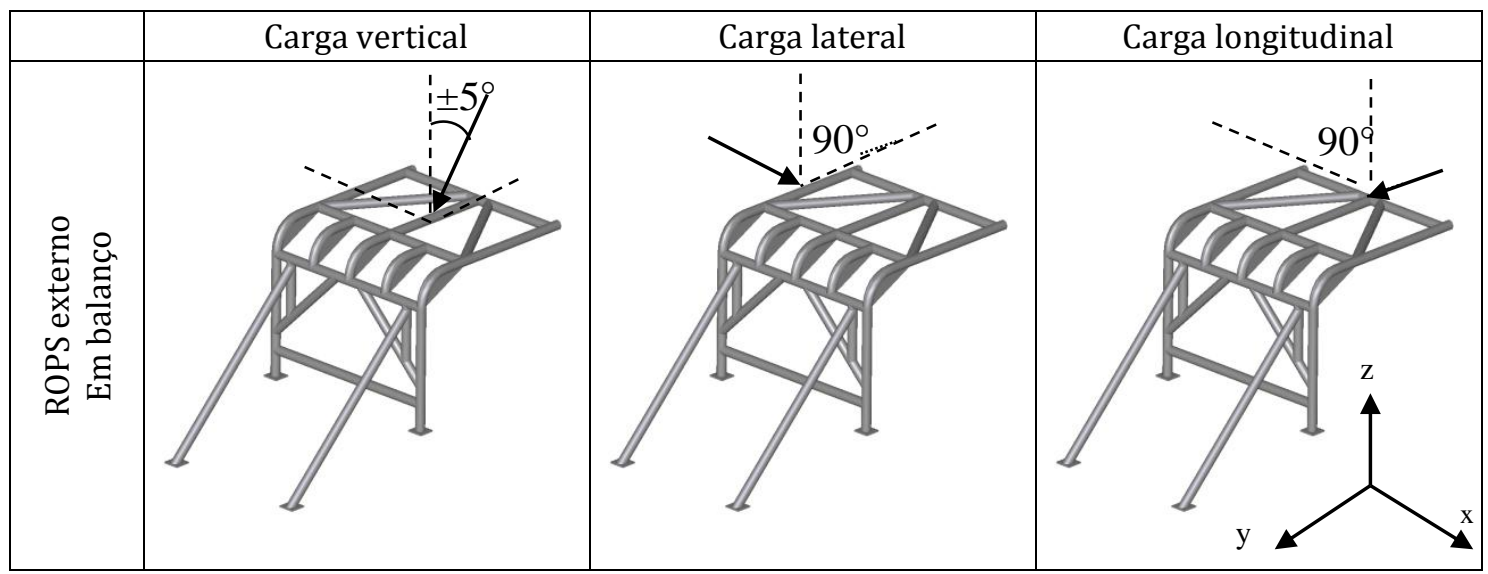

Figura 5 - Pontos de aplicação das cargas vertical, lateral e longitudinal.

Para que fosse possível verificar as deformações da estrutura após cada incremento de carga, a mesma foi monitorada em cerca de dez pontos, conforme se vê na Figura 6 abaixo.

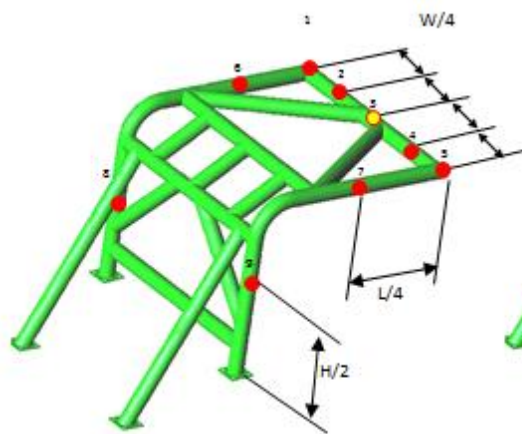

(a)

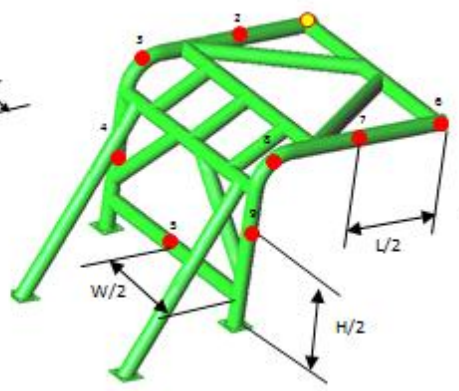

(b)

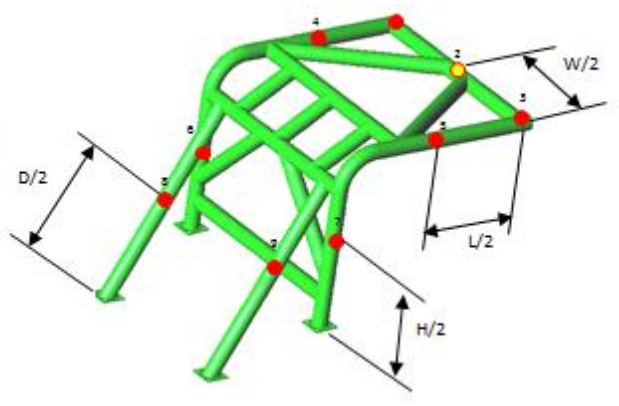

(c)

Figura 6 - Pontos de monitoramento de deformações para o ROPS externo, nas aplicações de cargas (a) verticais, (b) laterais e (c) longitudinais.

As deformações máximas foram registradas nos pontos de aplicação das forças, para as três direções, e em relação aos respectivos eixos cartesianos.

\subsubsection{Dimensionamento da estrutura ROPS e níveis máximos de deformação}

Durante a etapa de dimensionamento estrutural do ROPS interno, buscou-se prioritariamente determinar o tipo de material, diâmetro de tubo, bem com a espessura de parede dos mesmos.

Para isto, foram utilizadas as cargas de projeto - cargas sugeridas pelo protocolo Australiano - onde se tem nas direções vertical, lateral e longitudinal os valores citados na Tabela 1. Considera-se como massa de ambas as pick-ups o valor de aproximadamente $\mathrm{M}=2.750 \mathrm{Kg}$.

É importante destacar que as informações dimensões específicas de diâmetro externo e espessura de parede poderão ser substituídas de forma equivalente pelo valor 
no momento de inércia da seção transversal tubular. Destaca-se que a determinação de tal parâmetro é função dos dois primeiros citados, de acordo com a Eq. 1.

$$
I=\frac{\pi\left[D_{e}^{4}-\left(D_{e}-2 e\right)^{4}\right]}{64}
$$

onde " $D_{e}$ " representa o diâmetro externo do tubo e " $e$ " representa a espessura de parede. Qualquer combinação entre estas variáveis que gere o momento de inércia requerido, poderá ser então utilizada. Após a resolução do problema de equilíbrio estático foi possível determinar o momento de inércia necessário para a aplicação proposta, cujo valor é $1.72 \times 10^{-6} \mathrm{~m}^{4}$ (BEER, 2006).

De acordo com o protocolo Australiano, para seja mantido seguro o volume dentro de uma cabine, para os ocupantes, a estrutura ROPS não pode apresentar uma deflexão máxima nas três dimensões (lateral/vertical/longitudinal) de até $160 \mathrm{~mm}$, quando sujeita as cargas destacadas na Tabela 1. Obedecida esta condição de contorno, a estrutura possuirá então um nível de rigidez adequado (RMA Group, 2005; ISO 3164, 1995).

Durante a avaliação estrutural, gráficos referentes à força aplicada versus o deslocamento ocorrido foram monitorados, de maneira a se controlar o nível de rigidez requerido para a estrutura. Além disso, segundos requisitos verificados nas simulações numéricas realizadas, e baseado em normas existentes, o material escolhido para a fabricação do protótipo deveria possuir um limite de escoamento na faixa de 345 à 610 MPa. Para tal, foram selecionadas as propriedades do aço FB 70, que possui módulo de elasticidade de $206 \mathrm{GPa}$, com limite de escoamento de $490 \mathrm{Mpa}$ e coeficiente de Poisson igual a 0.3 .

É importante ressaltar que a seleção de materiais com limite de escoamento na faixa inferior (345 MPa) iria resultar em uma seção transversal mais robusta para a estrutura, ou seja, maiores diâmetro externo e espessura da seção tubular. Isto poderia acarretar em uma estrutura com elevado peso. Desta forma, recomendou-se uma ponderação entre as propriedades dos materiais disponíveis e as dimensões estruturais de maneira a se obter uma estrutura adequada.

1.2. Análises de resultados numéricos e ensaios em bancada de testes

\subsubsection{Análise das deformações da estrutura ROPS via simulações numéricas}

Nesta etapa do dimensionamento, foram coletados dados oriundos de simulações numéricas realizadas através do Método de Elementos Finitos (COOK, MALKUS, PLESHA, 2002) utilizando-se da ferramenta computacional ANSYS ${ }^{\circledR}$. Para isto, o modelo CAD da estrutura ROPS foi previamente modelado, conforme se vê na Figura 3-a.

Para análise do comportamento elasto-plástico da estrutura, utilizou-se o modelo de von Mises (BEER, 2006), bem como considerou-se inicialmente o material como perfeitamente plástico (REES, 2006).

O valor mais crítico de deformação encontrada, para a carga vertical equivalente a quatro vezes o peso do veículo, obedecendo aos mesmos preceitos de 
"local de aplicação", foi de $100 \mathrm{~mm}$, ou seja, abaixo do valor limítrofe sugerido pelo protocolo Australiano.

\subsubsection{O aparato experimental e procedimento de testes}

Para os ensaios experimentais, foi desenvolvida uma bancada de teste composta pelas seguintes partes: um pórtico para aplicação de cargas vertical e lateral, um pórtico para aplicação de carga longitudinal, uma mesa de apoio para fixação das estruturas de proteção (estrutura a ser ensaiada), três atuadores hidráulicos com capacidade nominal de 25 toneladas para carga vertical, 10 toneladas para a carga lateral e 5,0 toneladas para a carga longitudinal e um instrumento de leitura de coordenadas espaciais cartesianas. A Figura 7 mostra o aparato experimental disponível (COOPERRIDER, THOMAS, HAMMOUD, 1990).

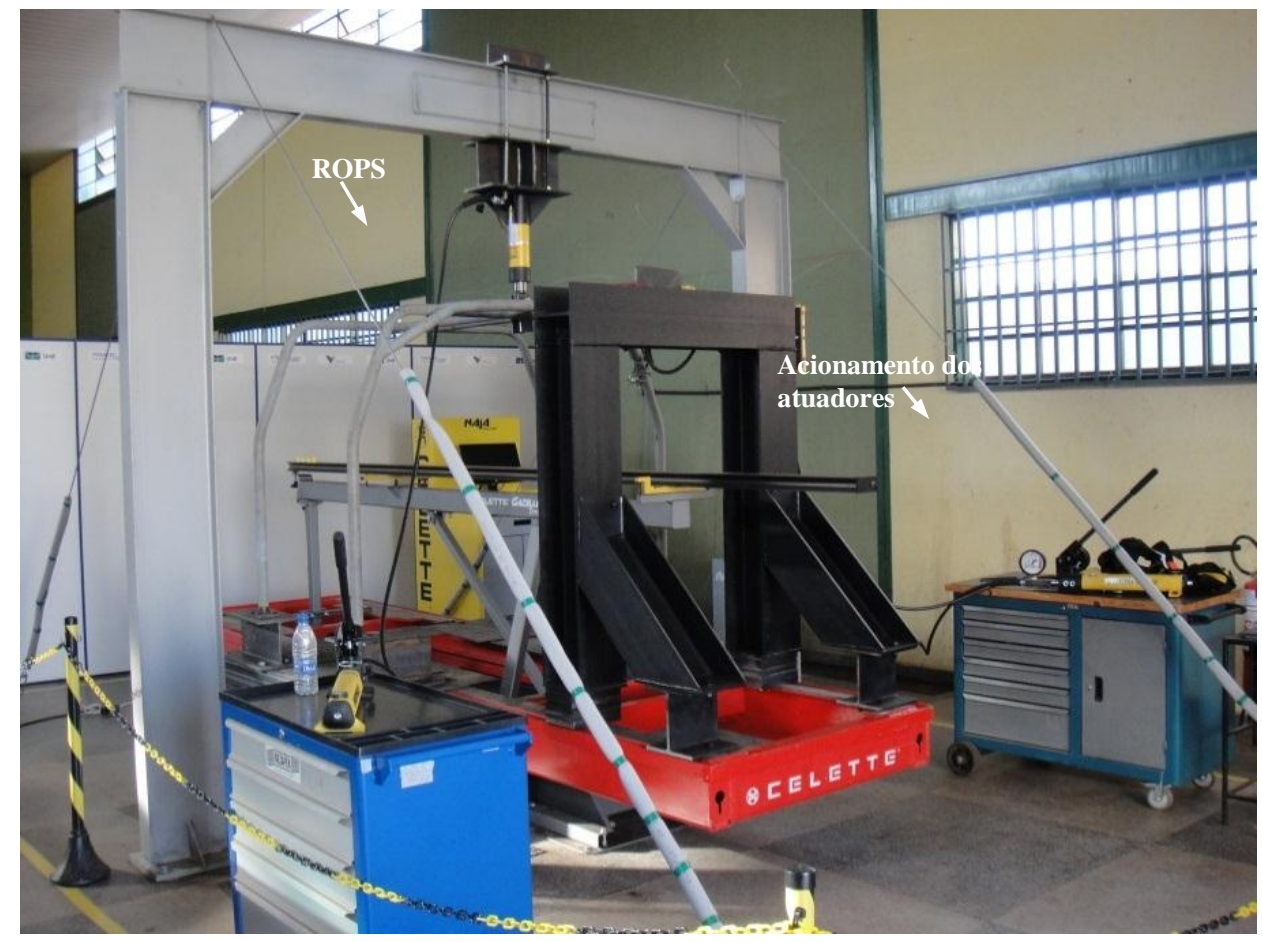

Figura 7 - Vista lateral da bancada de testes com a montagem de um ROPS interno.

A Figura 7 apresenta os pórticos e a estrutura da bancada de testes estático para ensaio do dispositivo de segurança em situação de capotamento (ROPS). A estrutura é formada por um pórtico simples, onde os dois pilares possuem altura de $2.700 \mathrm{~mm}$ e a viga comprimento de $3.300 \mathrm{~mm}$. O perfil utilizado é do tipo "I" com altura total de $300 \mathrm{~mm}$ e largura de mesa de $125 \mathrm{~mm}$. A espessura da mesa é de $16,2 \mathrm{~mm}$, enquanto a espessura da alma é de $10,8 \mathrm{~mm}$.

A Figura 8 apresenta um protótipo de ROPS interno com os três atuadores hidráulicos, que permitem aplicar carregamento em três direções principais: vertical, lateral e longitudinal. A imagem dos atuadores simultaneamente conectados ao ROPS é meramente ilustrativa, pois durante cada aplicação de força, os demais cilindros hidráulicos devem ser desconectados do sistema para evitar o travamento da estrutura. 


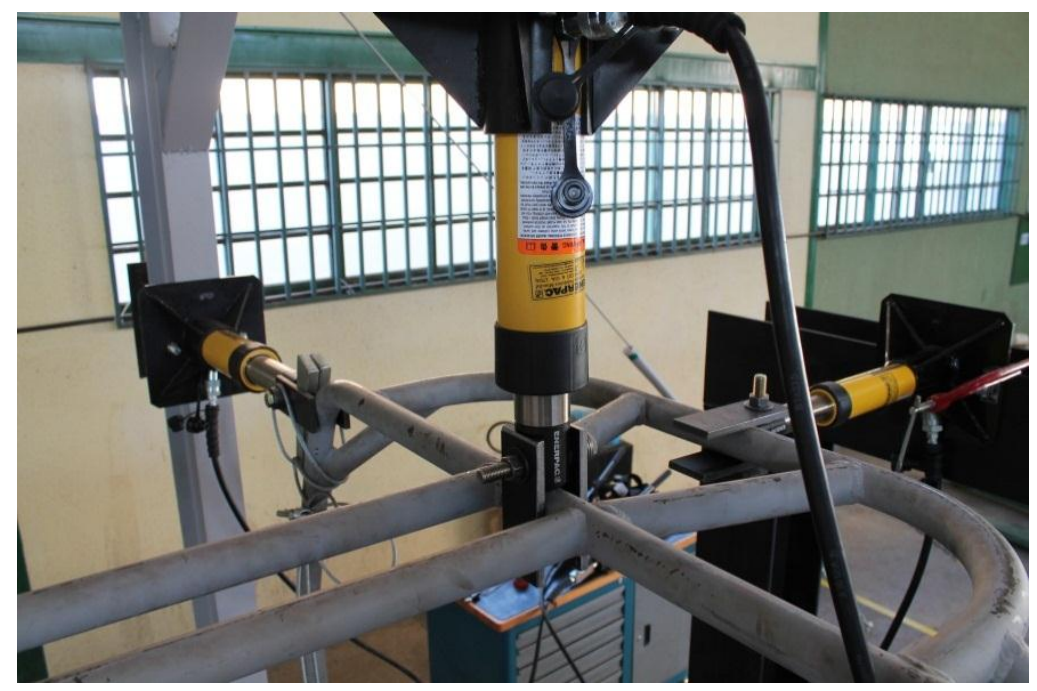

Figura 8 - Atuadores hidráulicos utilizados no teste típico de um ROPS, nas condições de aplicação de cargas verticais, laterais e longitudinais. Um modelo de ROPS com configuração interna está apresentado na imagem, no entanto um arranjo semelhante foi aplicado ao ROPS externo em questão.

A Figura 9 apresenta uma fotografia do atuador de cargas verticais, sobre o qual foi montado um transdutor de pressão para a leitura das cargas aplicadas. Todos três atuadores foram equipados com o mesmo transdutor de pressão.

A Figura 10 destaca o sistema de medição composto por um robô que se desloca sobre um trilho. Este robô possui uma haste giratória, que lhe confere mobilidade para alcançar os pontos de medição. Na extremidade de sua haste há uma esfera metálica que necessita ser posicionada em contato com a estrutura no momento da captura de pontos, via sistema wireless. Os pontos são enviados para um software que realiza os cálculos necessários para a obtenção das deflexões sofridas pela estrutura, em relação aos pontos colhidos antes do carregamento da mesma.

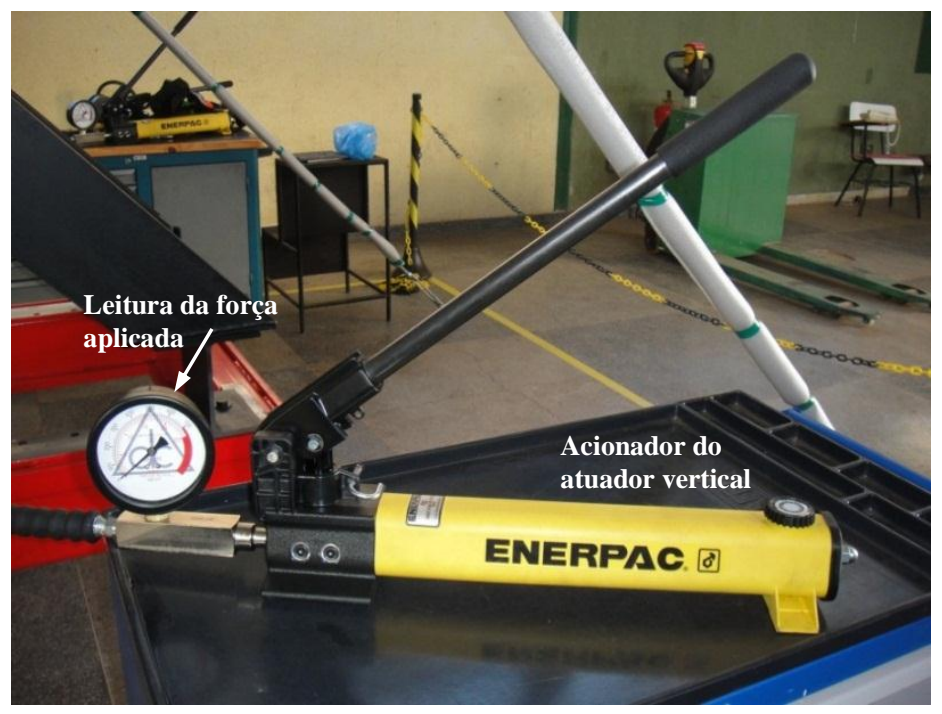

Figura 9 - Acionador do atuador hidráulico vertical equipado com o transdutor de pressão para leitura das cargas aplicadas. 


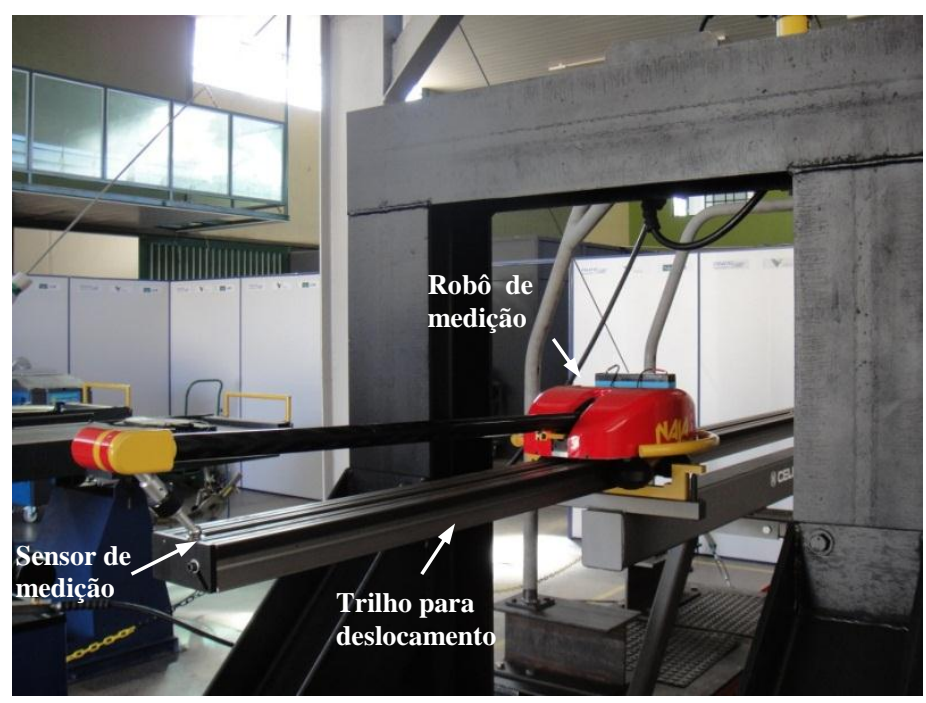

Figura 10 - Sistema de medição das coordenadas cartesianas espaciais dos pontos de interesse.

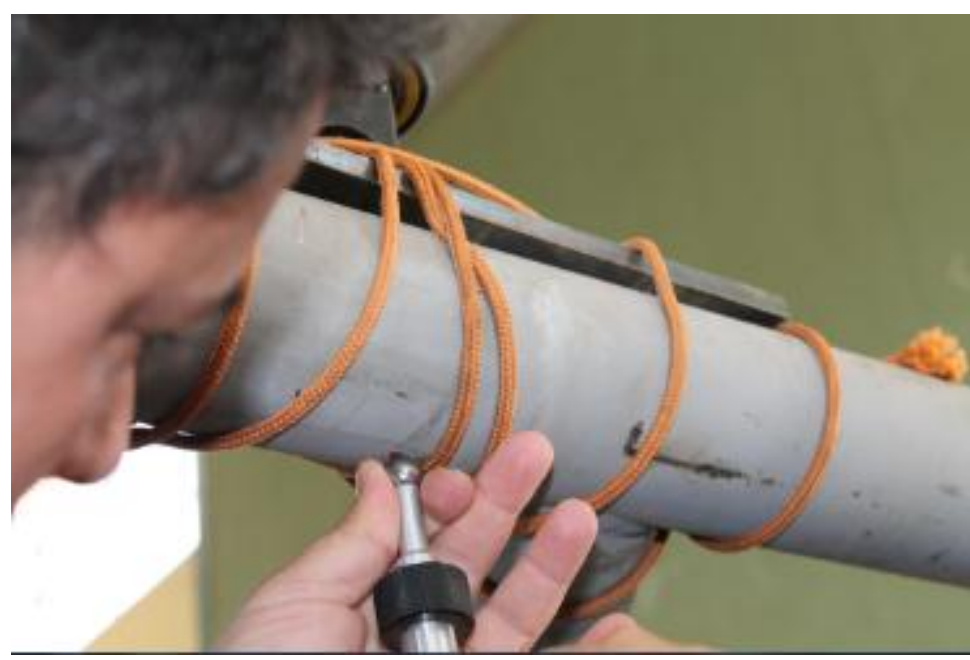

Figura 11 - Detalhe de medição no ponto de aplicação de cargas verticais na estrutura - ponto localizado da parte frontal do ROPS, no plano superior e ao longo da linha de simetria da estrutura.

Durante os ensaios em bancada, as cargas foram aplicadas, em todas as direções indicadas na Figura 5, de $1.000 \mathrm{~kg}$ em $1.000 \mathrm{~kg}$, até que o seu limite superior ou carga de projeto (ver Tabela 1) fosse ultrapassado. Após cada passo de carga aplicada, foram monitorados os níveis de deslocamentos da estrutura, nas direções cartesianas (x, y e z). A Figura 6 apresenta os pontos de monitoramento ao longo das estruturas, em cada condição de carga. O procedimento experimental está descrito abaixo:

1- Aplicação progressiva de cargas verticais; entre cada incremento as deformações da estrutura foram registradas pelo aparato experimental.

2- Após o último incremento de carga vertical, a estrutura foi liberada para então ser verificada a deformação permanente da mesma.

3- Em seguida o procedimento se repete para as cargas laterais e posteriormente para as cargas longitudinais. 
As cargas verticais, laterais e longitudinais foram aplicadas nesta ordem em obediência ao protocolo Australiano e demais bibliografias na área (CHEN, GUNTHER, 1993; JONES, PENNY, 1990). Na verdade, os valores indicados de 1,0, 1,5 e 4,0 vezes o peso do veículo representam fatores dinâmicos capazes de obter cargas estáticas equivalentes para teste. Esta sequencia de aplicação de cargas sugere a simulação de uma situação real de capotamento, onde o veículo sofreria impactos subsequentes até a sua completa imobilização.

\subsubsection{Resultados dos ensaios em bancada}

No gráfico da Figura 12 observa-se que o ROPS atingiu uma carga de nove toneladas força de carregamento vertical para a condição de contorno de deslocamento máximo vertical de $160 \mathrm{~mm}$. Após o descarregamento tem-se uma deformação permanente de 58,17 mm. Portanto para condição de carga o ROPS atingiu sua função.

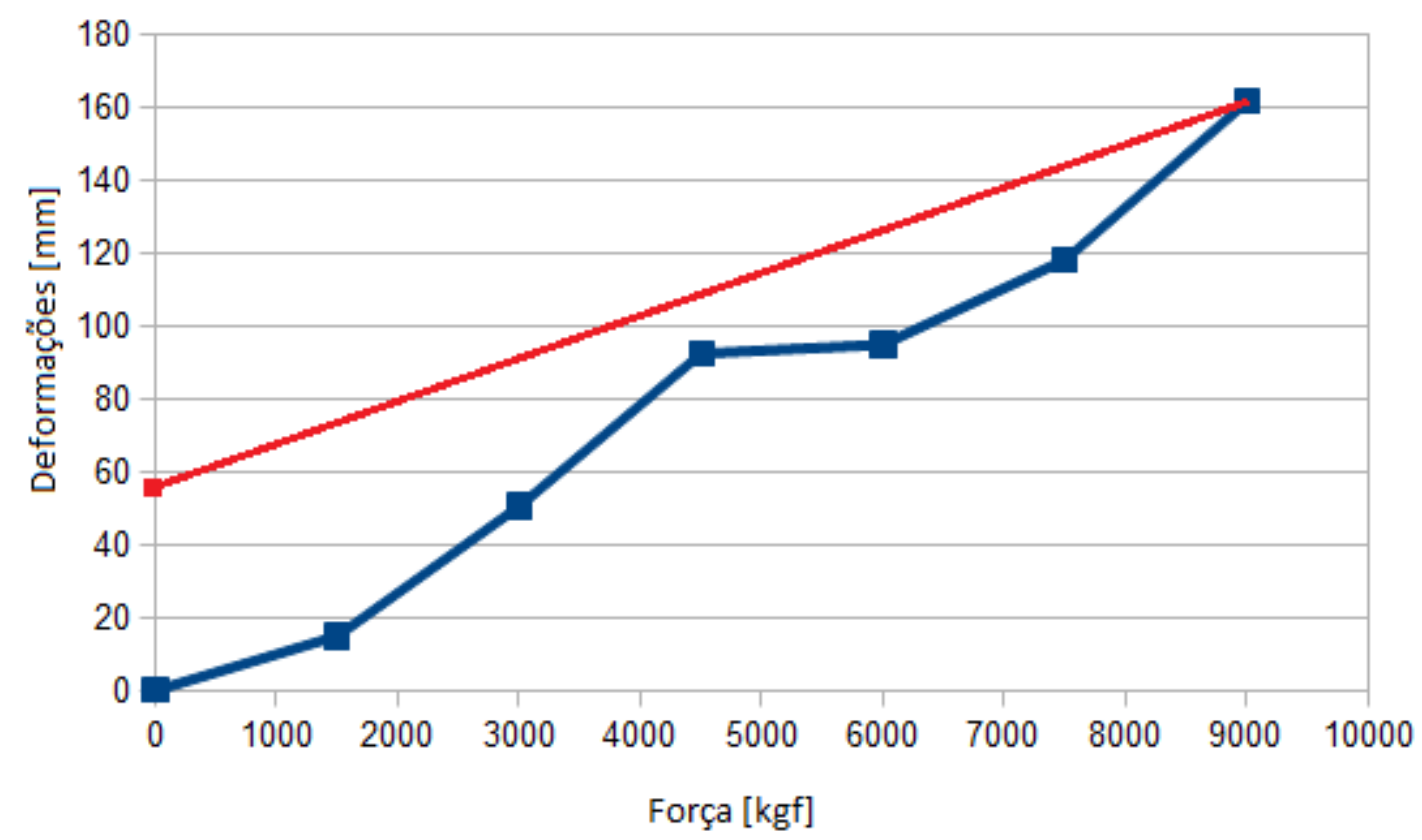

Figura 12 - Gráfico Deformação X Força Vertical Aplicada sobre o ROPS. Reta superior representa a deformação elástica com plastificação residual de $58,17 \mathrm{~mm}$.

Na Figura 13 observa-se o resultado para a deformação do ROPS na direção lateral. Neste carregamento o deslocamento máximo é $18 \mathrm{~mm}$. Para carregamento lateral o ROPS para condição de carga prevista o ROPS também atingiu sua função.

Para finalizar, na Figura 14 tem-se o resultado para a deformação do ROPS ao longo da direção longitudinal. Neste carregamento o deslocamento está baixo do previsto para o desempenho satisfatório no veiculo, com 1,79 mm. Portanto o ROPS atingiu sua função, apresentando depois do teste apenas $0,5 \mathrm{~mm}$ de deformação residual. 


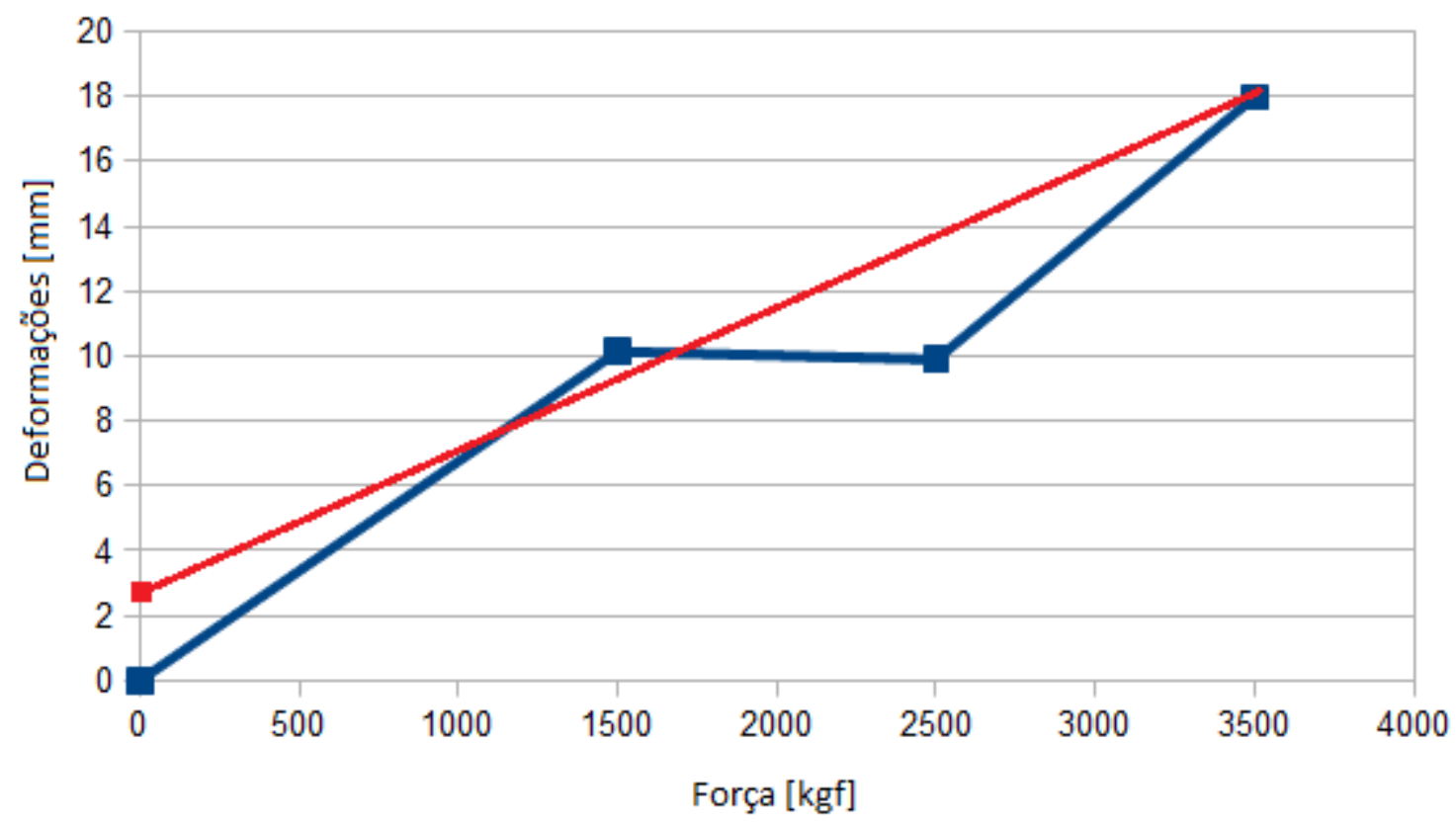

Figura 13 - Gráfico Deformação X Força Lateral Aplicada sobre o ROPS. Reta superior representa a deformação elástica com plastificação residual de $2,38 \mathrm{~mm}$.

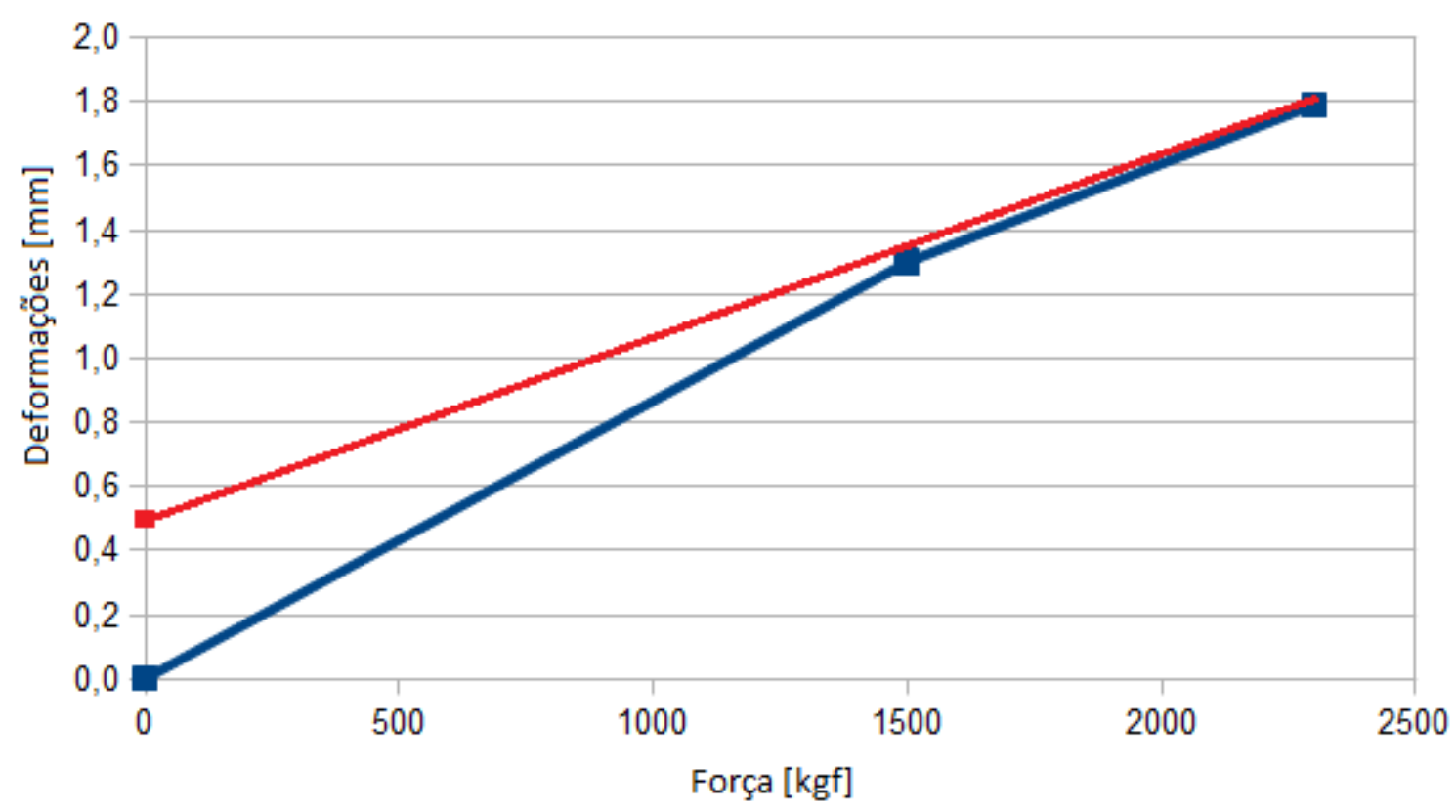

Figura 14 - Gráfico Deformação X Força Longitudinal Aplicada Sobre o ROPS. Reta superior representa a deformação elástica com plastificação residual de $0,50 \mathrm{~mm}$.

1.3. Instalação do protótipo de ROPS Interno em veículo para teste piloto

O ensaio dinâmico, conhecido pelo termo inglês crash test, é uma das mais importantes etapas dos testes de desenvolvimento deste projeto, por representar uma situação de capotagem veicular e, consequentemente, submeter o protótipo ROPS às cargas reais previstas para sua aplicação. O esquema geral utilizado no crash test, ou capotagem simulada, em questão se encontra descrito na Figura 15, abaixo. 
O teste de capotagem simulada foi realizado a uma velocidade de $60 \mathrm{~km} / \mathrm{h}$, sobre um piso de concreto de elevada rigidez, para que as energias envolvidas nos impactos fossem absorvidas em sua maior parte pelo veículo montado com o protótipo ROPS interno de confirmação. Durante o movimento uniforme do caminhão guincho, o veículo foi liberado para simular a capotagem (DODT, 1967; KLEIN, 1992).

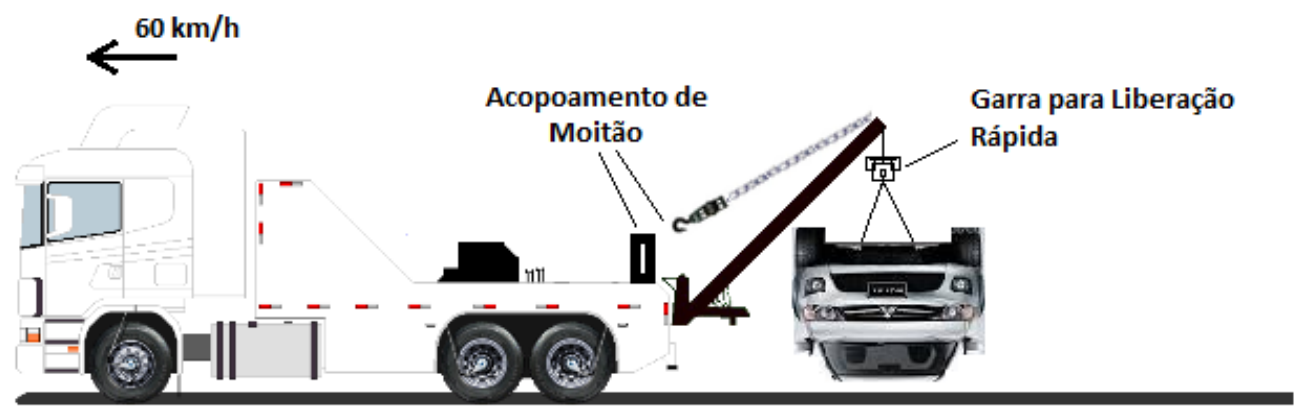

Figura 15 - Esquema para execução da capotagem simulada.
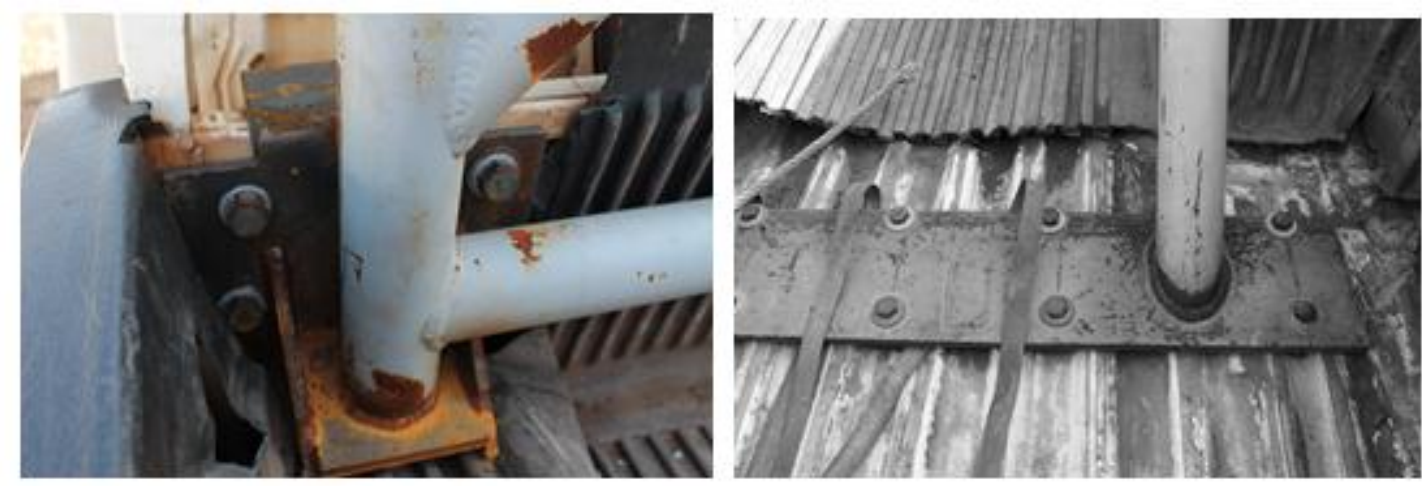

Figura 16 - Pontos de fixação do protótipo de confirmação utilizado para o teste piloto. As fixações foram realizadas com chapas acima e abaixo da caçamba do veículo, para as cargas no apoio fossem melhores distribuídas.

A Figura 16, acima, mostra em detalhe os pontos de fixação da estrutura sobre a caçamba da pick-up. À direita, nota-se que o ROPS se apoia sobre a caixa de rodas e sobre a borda superior da caçamba. Parafusos M16 foram utilizados para a montagem, em acordo com os cálculos apresentados a seguir.

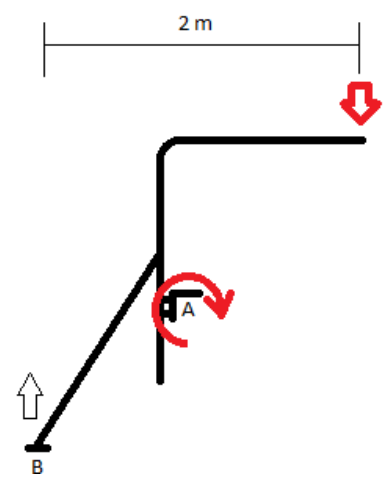

Resistência dos parafusos Aço 8.8:

$8 \times 100 \times 0,8=640 \mathrm{MPa}$

M16: fator de segurança $=2,35$

$A_{t}=(13,9 \mathrm{~mm})^{2} \times \pi / 4=151,8 \mathrm{~mm}^{2}$

$T_{t}=F / A_{t}=41.250 / 151,8=271,74 M P a$

(fator dinâmico sobre a carga $=4$; Carga $=11.000 / 8 \mathrm{Kg}$ )

Figura 17 - Dimensionamento de parafusos para fixação do ROPS externo no assoalho da caçamba. 


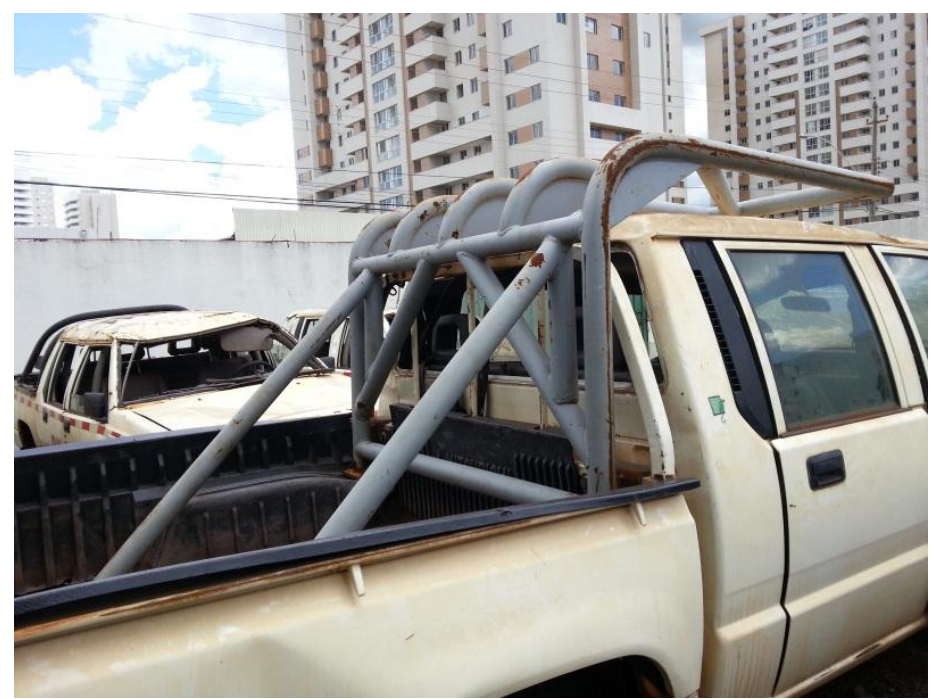

Figura 18 - Visualização do veículo montado com o ROPS externo após a simulação de capotamento.

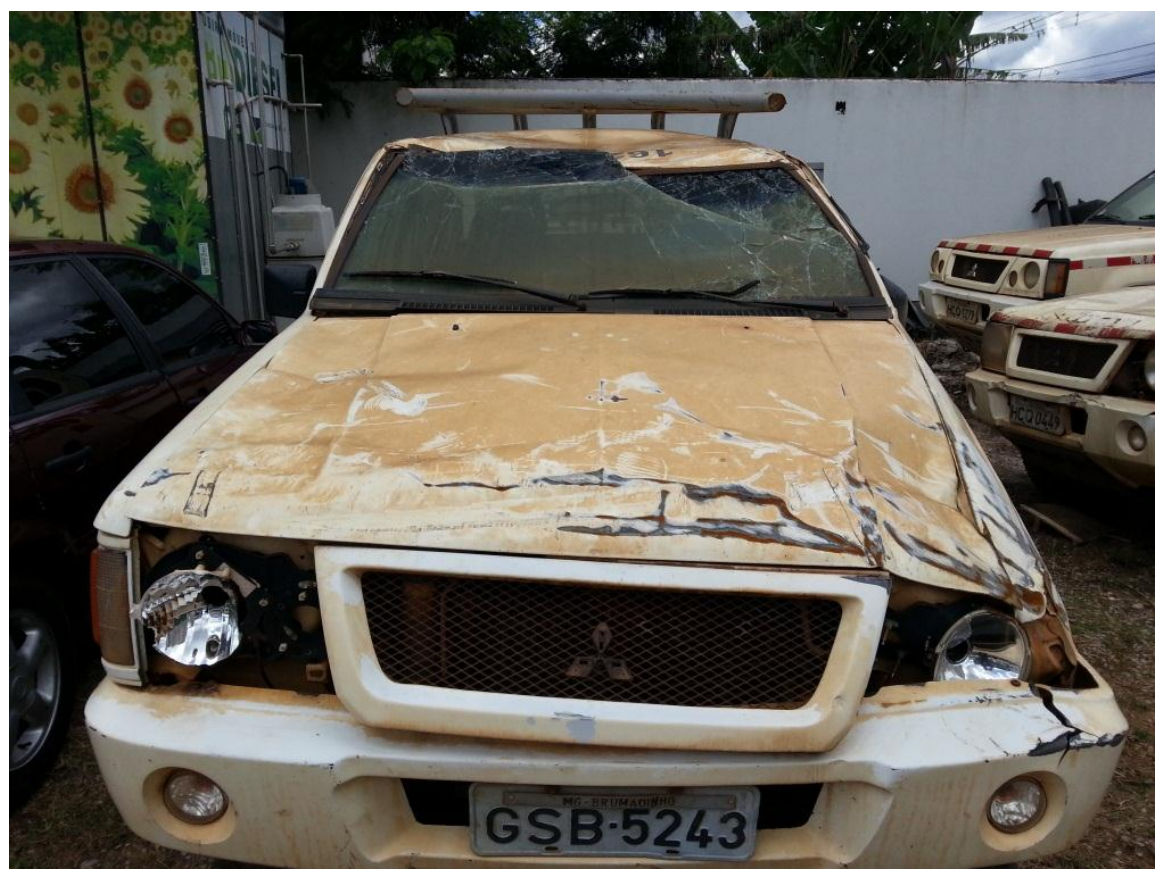

Figura 19 - Imagens do veículo após a realização do teste piloto: a simulação de capotamento.

Na Figura 18 está apresentado o veículo montado com o ROPS externo após a simulação de capotamento. Observa-se que o ROPS se mantem integro em sua posição, fato que comprova a adequada fixação do mesmo na caçamba do veículo.

Na Figura 19 é possível perceber a partir das deformações frontais sofridas pelo veículo que o primeiro impacto ocorreu provavelmente sobre o pitar frontal do veículo, no lado do motorista. Muito embora este pilar esteja mais deformado do que o outro pilar frontal ainda se percebe que o teto da cabine está praticamente plano, fato este que se explica a partir da formação do plano simulado vertical - o plano simulado vertical protege os ocupantes do veículo do esmagamento de cabine, que possivelmente aconteceria sem a instalação do ROPS. Os resultados para os testes pilotos foram bastante satisfatórios no que se diz respeito à robustez do ROPS. 


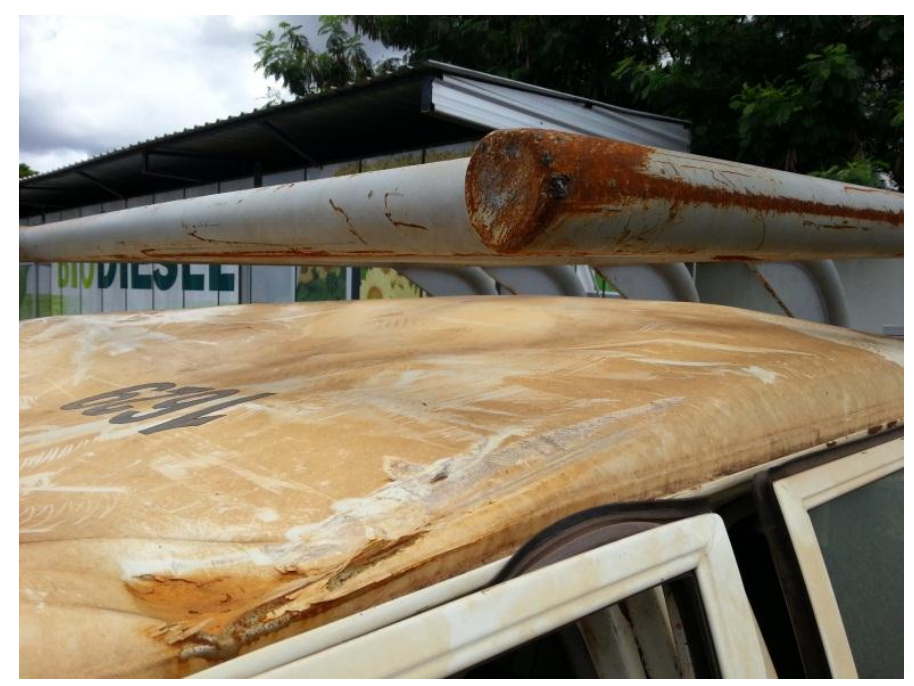

Figura 20 - Foto das marcas de colisão do ROPS no Teto do veiculo produzida durante o teste de capotamento.

Na Figura 20 é possível verificar prováveis marcas do ROPS sobre o teto do veículo, ou seja, o ROPS pode ter se deformado elasticamente até o ponto de colisão com a cabine. Entretanto, as deformações sore o teto do veículo nem mesmo atinge a porta de maneira significativa, garantindo ao piloto um volume seguro dentro da cabine.

\section{CONCLUSÃO}

Este trabalho apresenta alguns dos principais resultados obtidos pelo projeto ROPS solicitado, em configuração interna, desenvolvido para a pick-up 4x4 MITSUBISHI L200 GL pela Universidade de Brasília Campus Gama. Os testes estáticos e dinâmicos realizados demonstraram que o protótipo desenvolvido neste projeto atende aos critérios de desempenho estabelecidos pelas normas e protocolos internacionais referentes ao tema. O aço FB 70 selecionado para a fabricação e fornecido pela V\&M do Brasil apresentou excelente comportamento nas operações de dobramento e soldagem, com deformações insignificantes nos testes estáticos e dinâmicos efetuados.

Uma das pick-ups cedidas pela empresa solicitante foi submetida ao teste de simulação de capotamento em posição invertida, a $60 \mathrm{~km} / \mathrm{h}$, executado conforme mostrado na Figura 16. Após o teste, foram observados os seguintes aspectos estruturais:

1) Pode-se observar a formação de um plano simulado vertical, entre o capô do veículo e a parte superior frontal do ROPS externo. Este plano é responsável pela proteção dos ocupantes do veículo em uma eventual situação de capotamento.

2) O ROPS externo se manteve aproximadamente em sua mesma posição inicial após a realização da simulação de capotamento, fato que constata a integridade das fixações realizadas sobre o assoalho da caçamba do veículo.

Vale ressaltar que, por razões óbvias, o ROPS externo em balanço não implica em problemas de ergonomia para os ocupantes do veículo. Por outro lado, é muito importante que a estabilidade do veículo seja avaliada antes de sua utilização, pois o centro de gravidade pode sofrer alterações significativas. Tal problema foi estudado e resolvido em outra etapa deste 
projeto, mediante ao uso de ferramentas computacionais comerciais, e poderá ser retratado em detalhes em trabalhos futuros.

\section{REFERÊNCIAS}

[1] RMA Group. Light Vehicle Rollover Protection Structure (ROPS) - Test Protocol. Disponível em http://www.miningrops.com.au/downloads/test_protocol_RMA.pdf. Acesso em: 27/05/2014 às $15 \mathrm{~h}$.

[2] NBR NM - ISO 3471: Máquinas Rodoviárias - Estruturas Protetoras Contra Acidentes na Capotagem - Ensaios de laboratório e Requisitos de Desempenho, 2000.

[3] SAE J 1119 - Steel Products for Rollover Protective Structures (ROPS) and Falling Object Protective Structures (FOPS), 2008.

[4] FRIEDMAN, D. and Nash, C. Advanced Roof Design for Rollover Protection, $17^{\text {th }}$ ESV 01-S12-W-94, 2001.

[5] HERST, B., FORREST, S. and MEYER, S.E. Strenght Improvements to Automotive Roof Components, SAE 98029,1998.

[6] ISO 3164: Earth-moving machinery - Laboratory evaluations of protective structures Specifications for deflection-limiting volume, 1995.

[7] BEER, F. P. et al. Resistência dos Materiais, 4a ed. McGraw Hill, 2006.

[8] COOK, R. D., MALKUS, D. S., PLESHA, M. E., Witt, R. J., Concepts And Applications Of Finite Element Analysis, John Wiley \& Sons, 4 ed., 2002.

[9] REES, D.W.A. Basic Engineering Plasticity, Elsevier Ltd, 2006.

[10] COOPERRIDER, N. K., THOMAS, T.M. and HAMMOUD, S.A. Testing and Analisys of Vehicle Rollover Behavior, SAE 900366, 1990.

[11] CHEN, H. F. and GUNTHER, D.A. Modelling of Rollover Sequences, SAE 931976, 1993.

[12] JONES, I.S. and PENNY, M.B. Engineering Parameters Related to Roll Over Frequency, SAE 900104, 1990.

[13] SYSON, S. R. Occupant to roof contact: roll-overs and drop tests, SAE 950654, in advances in Occupant Protection Technologies for the mid Nineties, SAE SP 1077, Society of Automotive Engineers, 1995.

[14] FMVSS 216: Federal Motor Vehicle Safety Standards, Roof Crash Resistance. Disponível em http://www.nhtsa.gov/cars/rules/rulings/roofcrushnotice/216nprm-to-fr.html. Acesso em: 27/05/2014 às $15 \mathrm{~h}$.

[15] DODT, R. C. Accidents Reviews: Rollovers, Ford International Document from the Automotive Safety Research Office, Report N0 S-87-36, 30 November 1967.

[16] KLEIN, T.M. A Statistical Analyis of Vehicle Rollover Propensity and Vehicle Stability, SAE 920584, 1992. 